\title{
Correction to: Stress shadow, stress triggering, and recent earthquake activity in the Kashmir Himalaya, India
}

\author{
R. Arun Prasath • Mithila Verma • \\ Brijesh K. Bansal
}

Published online: 2 March 2022

(C) The Author(s), under exclusive licence to Springer Nature B.V. 2022

Correction to: Journal of Seismology (2021) 26:167-179 https://doi.org/10.1007/s10950-021-10067-4

The original version of the article unfortunately contained mistakes. The figure captions for Figures 1, 5, and 6 should be changed from two-column to onecolumn layout in order to conform to the standard format.

The original article has been corrected.

Publisher's note Springer Nature remains neutral with regard to jurisdictional claims in published maps and institutional affiliations.

The original article can be found online at https://doi.org/ 10.1007/s10950-021-10067-4.

R. A. Prasath $(\bowtie) \cdot$ M. Verma $\cdot$ B. K. Bansal

Seismology/Geosciences Division, Ministry of Earth

Sciences, New Delhi, India

e-mail: devanthran@hotmail.com

B. K. Bansal

Civil Engineering Department, Indian Institute

of Technology Delhi, New Delhi, India 